\title{
Pengembangan Data Warehouse Menggunakan Pendekatan Data-Driven untuk Membantu Pengelolaan SDM
}

\author{
Mujiono* $^{* 1}$, Aina Musdholifah ${ }^{2}$ \\ ${ }^{1}$ Badan Kepegawaian Daerah Kota Tarakan, Jl.Kalimantan No.1 SKIP \\ ${ }^{2}$ Jurusan Ilmu Komputer, FMIPA UGM, Yogyakarta \\ e-mail: ${ }^{* 1}$ mujiono.tarakan@gmail.com, ${ }^{2}$ aina_m@ugm.ac.id
}

\begin{abstract}
Abstrak
Dasar dari reformasi birokrasi adalah reformasi pengelolaan SDM. Salah satu faktor pendukungnya adalah pengembangan database pegawai. Untuk mendukung pengelolaan SDM diantaranya dibutuhkan data warehouse dan tool kecerdasan bisnis. Data warehouse adalah konsep penyimpanan data terintegrasi yang handal untuk memberi dukungan kepada seluruh kebutuhan analisis data. Dalam penelitian ini dikembangkan data warehouse dengan menggunakan pendekatan data-driven dengan sumber data berasal dari SIMPEG, SAPK dan presensi elektronik. Data warehouse dirancang menggunakan nine steps methodology dan dituangkan dalam notasi unified modeling language (UML). Extract transform load (ETL) dilakukan dengan menggunakan Pentaho Data Integration dengan menerapkan peta transformasi. Selanjutnya untuk membantu pengelolaan SDM, dibangun sistem untuk melakukan online analitical processing (OLAP) berbasis web guna mempermudah memperoleh informasi. Dalam penelitian ini dihasilkan framework pengembangan program aplikasi BI dengan asitektur Model-View-Controller (MVC) dan operasi OLAP dibangun menggunkan pembangkit query dinamis, PivotTable, dan HighChart untuk menyajikan infomasi tentang PNS, CPNS, Pensiun, Kenpa dan Presensi.
\end{abstract}

Kata kunci-data warehouse, pengelolaan SDM, Model-View-Controller (MVC), query dinamis

\begin{abstract}
The basis of bureaucratic reform is the reform of human resources management. One supporting factor is the development of an employee database. To support the management of human resources required including data warehouse and business intelligent tools. The data warehouse is an integrated concept of reliable data storage to provide support to all the needs of the data analysis. In this study developed a data warehouse using the data-driven approach to the source data comes from SIMPEG, SAPK and electronic presence. Data warehouses are designed using the nine steps methodology and unified modeling language (UML) notation. Extract transform load (ETL) is done by using Pentaho Data Integration by applying transformation maps. Furthermore, to help human resource management, the system is built to perform online analytical processing (OLAP) to facilitate web-based information. In this study generated BI application development framework with Model-View-Controller (MVC) architecture and OLAP operations are built using the dynamic query generation, PivotTable, and HighChart to present information about PNS, CPNS, Retirement, Kenpa and Presence
\end{abstract}

Keywords-data warehouse, human resources management, Model-View-Controller (MVC), dynamic query

Received February $25^{\text {th }}, 2015$; Revised January ${ }^{\text {st }}$, 2016; Accepted January $20^{\text {th }}, 2016$ 


\section{PENDAHULUAN}

$\mathrm{R}$ eformasi birokrasi adalah strategi untuk membangun aparatur negara agar lebih berdayaguna dan berhasil guna. Menurut [1] salah satu pendekatan pembangunan SDM aparatur yang paling utama adalah melalui reformasi pengelolaan SDM dengan penguatan implementasi teknologi informasi. BKD Kota Tarakan telah mengimplementasikan banyak sistem informasi secara online (online transaction processing) untuk mengelola SDM [2], namun pimpinan masih kesulitan dalam mendapatkan informasi dengan mudah dan cepat secara online (OLAP) [3]. Permasalahan tersebut disebabkan belum tersedianya data warehouse atau sumber data yang handal $[1,4]$ untuk mendukung analisis $[5,6]$.

Data warehouse adalah sumber data yang handal yang menyediakan semua kebutuhan analisis keputusan [7]. Data warehouse merupakan central point pengingrasian banyak database [8,9]. Implementasi data warehouse sangat luas dan terbuka di lingkungan pemerintahan [4] sebab pemerintah telah memiliki banyak sumber data untuk diolah menjadi informasi lintas departemen yang komprehensif [10]. Beberapa implementasi data warehouse [11,12] dapat meningkatkan kinerja pemerintah, sebagian yang lain $[4,10]$ menjadi perangkat lunak kecerdasan bisnis.

Keberhasilan implementasi data warehouse setidaknya dipengaruhi oleh dua faktor yaitu desain data warehouse dan faktor manajemen. Pada faktor desain, ada dua masalah yang biasa timbul [13] yaitu (1) masalah pemodelan dimensi untuk memfasilitasi dan mengontrol operasi analisis, dan (2) berhubungan dengan ragam arsitektur data warehouse yang dapat diterapkan. Sedangkan faktor manajemen [14] terkait dengan kemampuan tim dan kemampuan manajemen dalam menghadapi masalah yang akan timbul dalam proyek data warehouse.

Menurut [15], terdapat 3 hal yang dapat mendukung suksesnya proyek data warehouse, yaitu:

1. Desain arsitektur yang bagus yang dapat menjamin performa dan stabilitas untuk implementasi disaat ini dan masa mendatang.

2. Semua komponen meliputi user interface, penyimpanan data, aplikasi, logika program dan jaringan harus dapat dioperasikan dengan mudah dan fleksibel.

3. Model desain data yang konsisten dibangun agar memudahkan mengelola bagaimana mengektrak data dari sumbernya.

\section{METODE PENELITIAN}

Pengembangan data warehouse di BKD Kota Tarakan mengunakan pendekatan data driven dimulai dengan melakukan kajian kebutuhan informasi dan ketersediaan data. Berdasarkan hasil analisis kebutuhan, analisis sistem dan pengamatan dokumen-dokumen selanjutnya dirancang sistem ETL, data warehouse dan aplikasi OLAP. Dalam pengembangan data warehouse, sumber data adalah pertimbangan utama setelah kebutuhan pengguna.

\subsection{Analisa kebutuhan}

BKD Kota Tarakan membutuhkan informasi untuk membantu pengelolaan SDM. Informasi tersebut bersumber dari SIMPEG, SAPK, dan presensi elektronik. Informasi yang dibutuhkan adalah informasi jumlah PNS, pensiun, kenaikan pangkat, CPNS dan presensi yang dioperasikan dalam berbagai sudut pandang analisis.

\subsection{Analisis sumber data}

SIMPEG adalah program aplikasi berbasis web untuk mengelola SDM di BKD Kota Tarakan. Basis data SIMPEG adalah MySQL yang berisi data kepegawaian PNS Kota Tarakan. Field yang dibutuhkan untuk membuat informasi PNS adalah TGL_LAHIR, JENIS_KEL,

IJCCS Vol. 10, No. 1, January 2016: $1-10$ 
AGAMA, STAT_KAWIN, PEND_AKHIR, UNIT_KERJA, ESEL_KINI, NAMA_JAB, DIKLATJAB, GOL_AKHIR.

Sistem aplikasi pelayanan kepegawaian (SAPK) adalah sistem informasi kepegawaian yang standar dan terintegrasi antara BKN dengan unit pengelola kepegawaian instansi pusat maupun daerah (BKD). Data yang dijadikan sumber untuk data warehouse diperoleh dengan melakukan export data dari masing-masing layanan melalui menu yang disediakan SAPK. Terdapat 3 sumber data yang diperlukan dari SAPK untuk memenuhi kebituhan informasi BKD Tarakan yaitu data CPNS, Kenaikan pangkat, dan pensiun. Adapun field yang dibutuhkan untuk membuat informasi CPNS adalah TGL LAHIR, JENKEL, AGAMA, STATUS PERKAWINAN, TKT PENDIDIKAN, JABATAN CPNS, UNIT KERJA, GOLRU, TMT CPNS, TMS/BTL. Field untuk membuat informasi pensiun adalah Jenis Pensiun, NIP Baru, Tanggal Lahir, Golongan Ruang Baru, TMT Pensiun. Field untuk membuat informasi kenaikan pangkat adalah JENIS KP, NIP BARU, PENDIDIKAN, GOLONGAN RUANG BARU, TMT GOLONGAN RUANG BARU, JABATAN BARU, UNIT KERJA.

Database presensi adalah catatan kehadiran PNS Kota Tarakan. Database presensi berbentuk file dbf dipergunakan sebagai data untuk membantu pengelolaan pemberian tunjangan perbaikan penghasilan (TPP). Adapun field yang dibutuhkan untuk membuat informasi presensi adalah TGL_ABSEN, POT_ABSEN_PER_HARI, KET_ABSEN, URUT_PANGKAT, NO_JABATAN.

\subsection{Desain sistem}

Untuk memenuhi kebutuhan informasi dibuat sistem data warehouse PNS BKD Kota Tarakan Gambar 1. Arsitektur sistem terdiri dari ETL sistem, data staging, data warehouse, sistem OLAP, dan sistem dashboard. Sistem ETL melakukan akuisisi data untuk data warehouse. Dalam proses persiapan data, proses transformasi dan pembersihan data dilakukan terhadap data sumber yang disimpan dalam tabel-tabel staging. Data dengan kualitas yang tertentu selanjutnya di load ke data warehouse untuk dapat dianalisis dengan sistem OLAP menggunakan sistem dashboard.

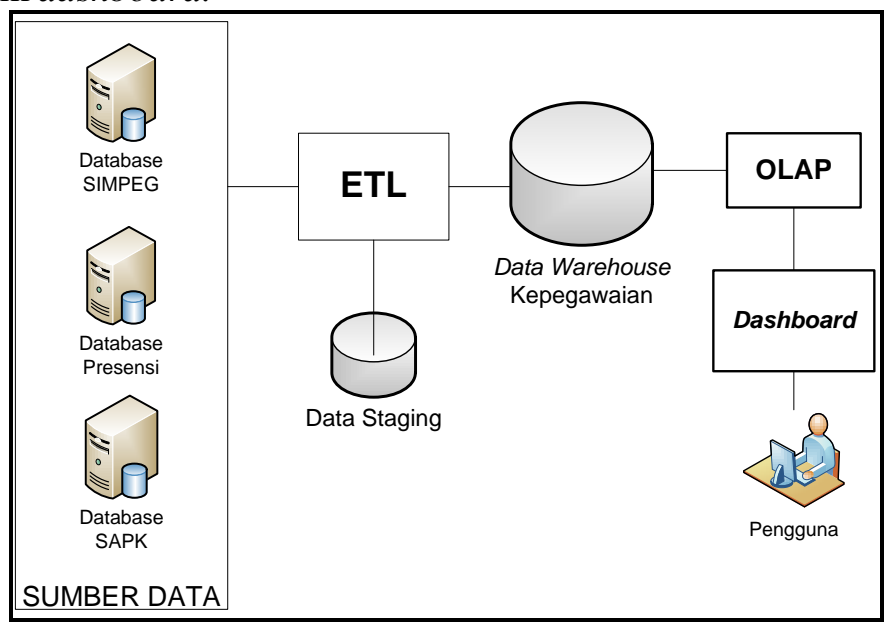

Gambar 1 Arsitektur sistem data warehouse

\subsubsection{Desain ETL}

Berdasarkan hasil analisis sumber data, selanjutnya dibuat desain untuk melakukan proses extract transform dan load (ETL). Secara umum proses ETL terdiri dari mengekstrak data ke file atau pembacaan langsung dari sumber data. Proses dilanjutkan dengan memilih field untuk memperoleh data yang dibutuhkan. Selanjutnya melakukan transformasi data. Data hasil transformasi di-load ke data staging dan diikuti load data akhir ke data warehouse. Adapun desain ETL disajikan dalam Gambar 2. 


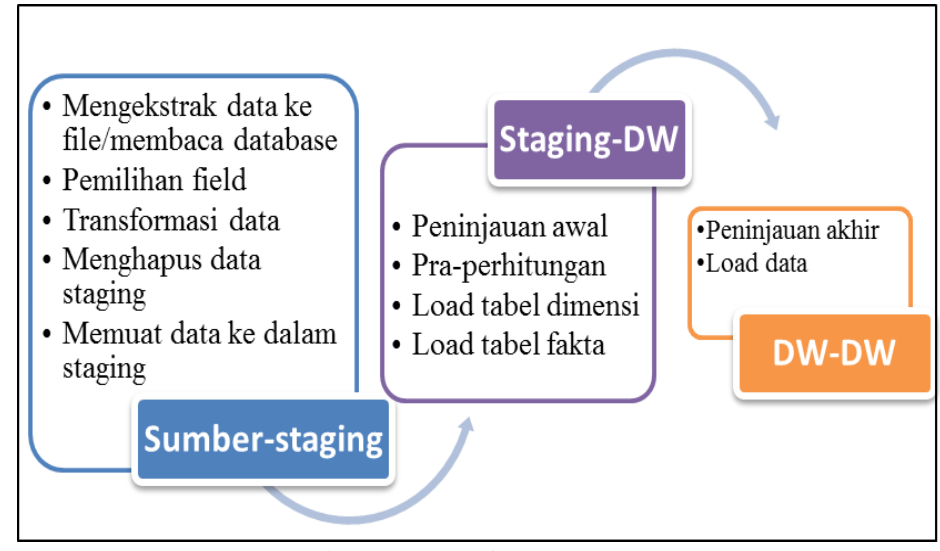

Gambar 2 Desain ETL

\subsubsection{Desain data warehouse}

Pengembangan data warehouse dilakukan dengan menggunakan nine-step methodology

[16] sebagai berikut:

1. Pemilihan proses (Choosing the Process)

Berdasarkan hasil analisis kebutuhan informasi dan sumber data yang tersedia, di ketahui 5 proses utama yang berkaitan dengan pengelolaan SDM di BKD Kota Tarakan yaitu pengelolaan PNS, pensiun, kenaikan pangkat, CPNS, dan presensi.

2. Pemilihan Grain (Choosing the Grain)

Adapun grain dalam rancangan data warehouse PNS BKD Kota Tarakan adalah sebagai berikut:

a. Grain dari fakta PNS adalah diklatpim, pangkat, eselon, jabatan, unit kerja, pendidikan, identitas pegawai, dan usia;

b. Grain dari fakta kenpa adalah jenis kenaikan pangkat, pendidikan, pangkat, unit kerja.

c. Grain dari fakta pensiun adalah jenis pensiun, pangkat, usia.

d. Grain dari fakta CPNS adalah identitas pegawai, usia, pendidikan, jabatan, unit kerja, pangkat, keterangan.

e. Grain dari fakta presensi pegawai adalah keterangan presensi, identitas pegawai, usia, pendidikan, eselon, jabatan, pangkat, unit kerja, TPP, dan potongan TPP.

3. Identifikasi dan menyesuaikan dimensi (Identifying and conforming the dimention)

Berdasarkan pemilihan grain, ditentukan dimensi untuk masing-masing fakta sebagaimana ditunjukkan pada Tabel 1.

Tabel 1 Grain dan dimensi

\begin{tabular}{|c|c|c|c|c|c|c|}
\hline NO & Dimensi & PNS & Kenpa & CPNS & Pensiun & Presensi \\
\hline 1 & Identitas Pegawai & $\sqrt{ }$ & & $\sqrt{ }$ & & $\sqrt{ }$ \\
\hline 2 & Pendidikan & $\sqrt{ }$ & $\sqrt{ }$ & $\sqrt{ }$ & & $\sqrt{ }$ \\
\hline 3 & Unit Kerja & $\sqrt{ }$ & $\sqrt{ }$ & $\sqrt{ }$ & & $\sqrt{ }$ \\
\hline 4 & Jabatan & $\sqrt{ }$ & & $\sqrt{ }$ & & $\sqrt{ }$ \\
\hline 5 & Eselon & $\sqrt{ }$ & & & & $\sqrt{ }$ \\
\hline 6 & Pangkat & $\sqrt{ }$ & $\sqrt{ }$ & $\sqrt{ }$ & $\sqrt{ }$ & $\sqrt{ }$ \\
\hline 7 & Diklatpim & $\sqrt{ }$ & & & & \\
\hline 8 & SK Kenpa & & $\sqrt{ }$ & & & \\
\hline 9 & SK CPNS & & & $\sqrt{ }$ & & \\
\hline 10 & Jenis Pensiun & & & & $\sqrt{ }$ & \\
\hline 11 & Usia & $\sqrt{ }$ & & $\sqrt{ }$ & $\sqrt{ }$ & $\sqrt{ }$ \\
\hline 12 & Presensi & & & & & $\sqrt{ }$ \\
\hline 13 & Waktu & $\sqrt{ }$ & $\sqrt{ }$ & $\sqrt{ }$ & $\sqrt{ }$ & $\sqrt{ }$ \\
\hline
\end{tabular}

4. Pemilihan fakta (Choosing the Fact)

fakta-fakta pengelolaan SDM di BKD Kota Tarakan ditentukan sebagai berikut: 
a. Fakta PNS adalah jumlah PNS yang didiskripsikan dengan identitas pegawai, pendidikan, unit kerja, jabatan, eselon, pangkat, diklatpim, dan usia.

b. Fakta kenaikan pangkat atau kenpa adalah jumlah kenpa yang didiskripsikan dengan pendidikan, unit kerja, pangkat, dan SK kenpa.

c. Fakta CPNS adalah jumlah CPNS yang didiskripsikan dengan identitas pegawai, pendidikan, unit kerja, jabatan, pangkat, SK CPNS, usia, dan keterangan.

d. Fakta pensiun adalah jumlah pensiun yang didiskripsikan dengan jenis pensiun, pangkat, dan usia.

e. Fakta presensi adalah jumlah kehadiran, jumlah potongan, jumlah TPP yang didiskripsikan dengan keterangan, identitas pegawai, usia, pendidikan, jabatan, eselon, pangkat, dan unit kerja.

5. Menyimpan pre-kalkulasi dalam tabel fakta (Storing pre calculation in the fact table

Pra-perhitungan untuk disimpan pada masing-masing tabel fakta, dinyatakan dengan relational algebra, sebagai berikut:

a. Pra-perhitungan untuk fakta PNS

jenis_kelamin, agama, status_kawin, usia, pendidikan, unit_kerja, jabatan, eselon, golru, diklatpim $\vartheta$ count(id) as jumlah (s_pns)

b. Pra-perhitungan untuk fakta kenpa

jenis_kenpa, golru, unit_kerja, pendidikan $\vartheta_{\text {count(id) as jumlah }\left(s \_k e n p a\right)}$

c. Pra-perhitungan untuk fakta CPNS

jenis_kelamin, agama, status_kawin, usia, golru, nama_jabatan, pendidikan, unit_kerja, keterangan $\vartheta$ count(id) as jumlah (s_cpns)

d. Pra-perhitungan untuk fakta pensiun

jenis_pensiun, usia, golongan_ruang, TMT $\vartheta$ count(id) as jumlah (s_pensiun)

e. Pra-perhitungan untuk fakta presensi

tanggal, jenis_kelamin, agama, status_kawin, pendidikan, jabatan, usia, eselon, golongan_ruang, unit_kerja, keterangan $\vartheta$ sum(JML) as Jumlah,sum(Potongan) as potongan,sum(TPP) as TPP (s_presensi)

6. Melengkapi tabel dimensi (Rounding out the duration of database)

Melengkapi tabel dimensi berguna untuk melengkapi informasi mengenai dimensi agar mudah difahami dan digunakan.

7. Memilih durasi dari database (Choosing the duration of the database).

Durasi database untuk data presensi adalah 1 tahun sedang untuk data PNS, pensiun, kenaikan pangkat dan CPNS adalah 5 tahun.

8. Melacak perubahan dimensi secara perlahan (Tracking slowly changing dimensions).

Dapat dilakukan dengan menganti nilai atribut atau menambahkan atribut baru seperti pada Gambar 3.

\begin{tabular}{|l|l|l|l|}
\hline \multicolumn{2}{|l|}{ Jenis } \\
\hline Struktural \\
\hline Fungsional U mum \\
\hline \multicolumn{2}{|l|}{ Fungsional Angka kredit } \\
\hline
\end{tabular}

Gambar 3 Perubahan atribut 
9. Menentukan prioritas dan mode dari query (Deciding the query priorities and the query modes)

Adalah perlu melakukan loading data sesuai kebutuhan, pembuatan index data, dan melakukan backup data.

Dari proses pengembangan data warehouse, selanjutnya dituangkan dalam desain konseptual dan desain logika untuk memberi gambaran sederhana mengenai data warehouse PNS yang dibangun. Secara konseptual data warehouse yang dibangun dapat digambarkan dengan menggunakan profil UML [17] seperti pada Gambar 4. Gambar 5 menunjukkan desain logika data warehouse yang dibangun.

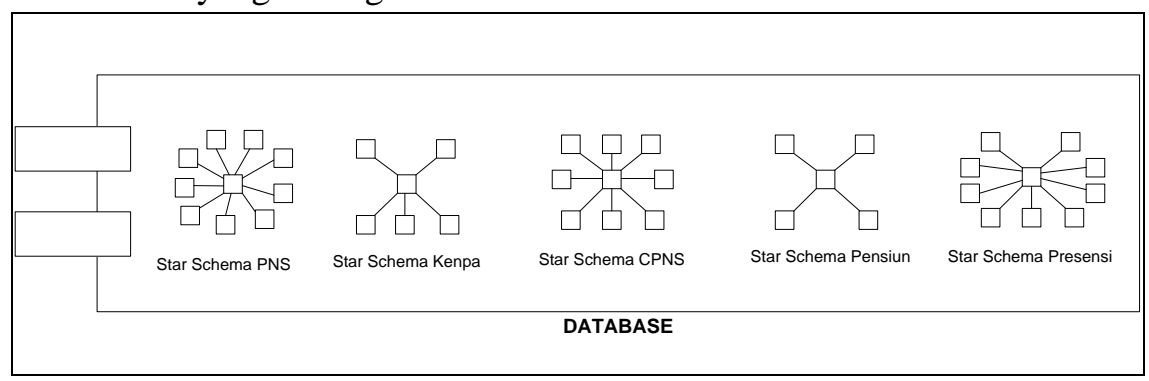

Gambar 4 Desain data warehouse

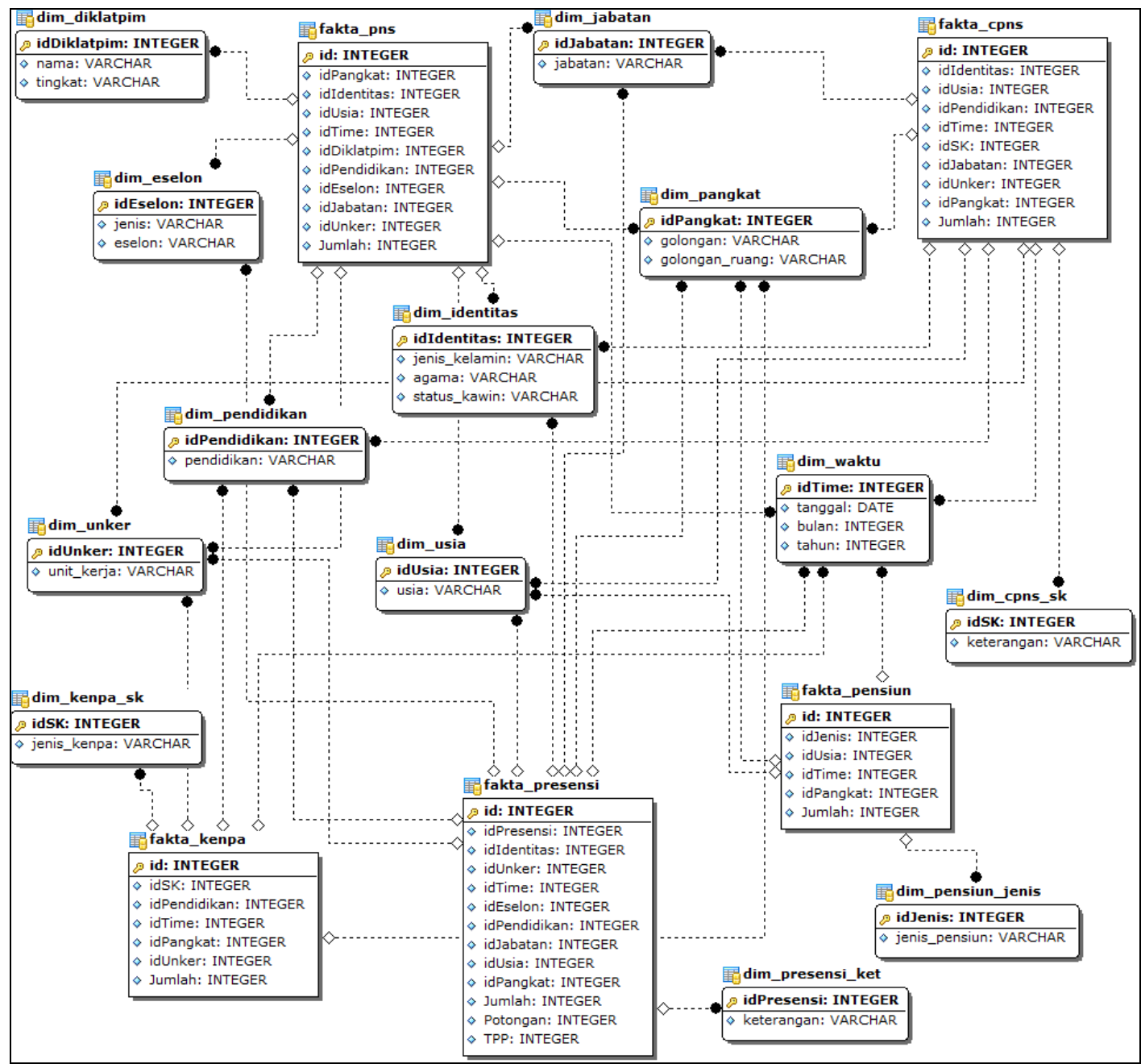

Gambar 5 Desain logika data warehouse

IJCCS Vol. 10, No. 1, January 2016: 1 - 10 


\subsubsection{Desain OLAP}

Berdasarkan desain data warehouse yang telah dibuat maka informasi dapat diperoleh dengan melakukan analisis dimensional. Analisis tersebut tersedia dalam 5 cube yaitu cube PNS, cube CPNS, cube Pensiun, cube Kenpa, dan cube Presensi seperti ditunjukkan dengan Gambar 6

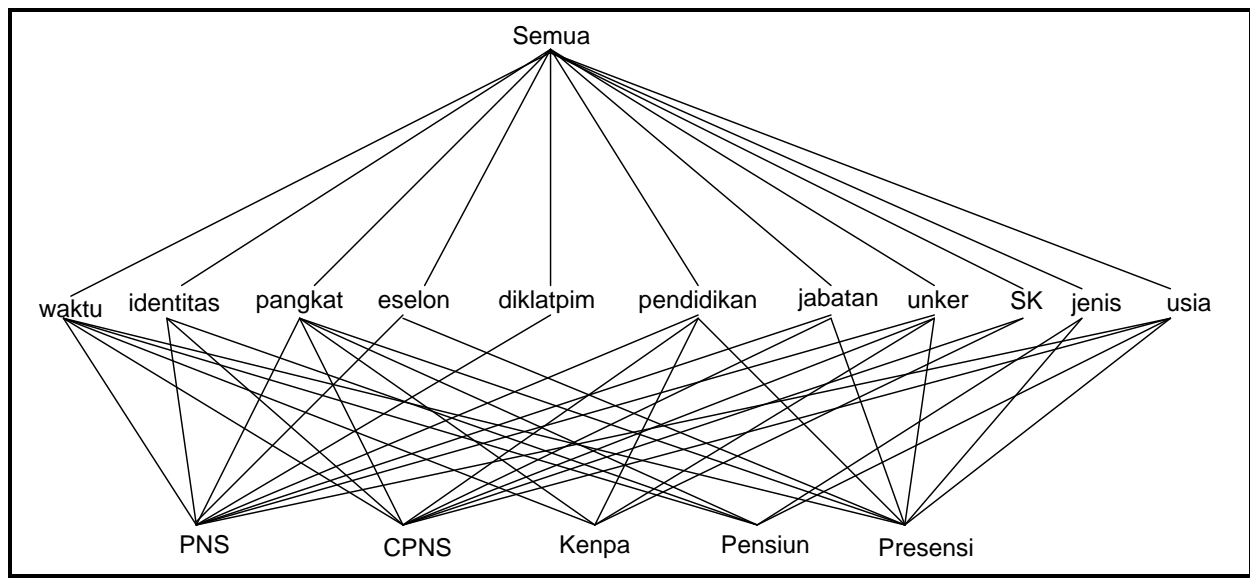

Gambar 6 Desain OLAP

\subsubsection{Desain dashboard}

Untuk memudahkan pengguna melakukan analisis maka di buat sistem dashboard. Adapun informasi yang sering dibutuhkan seperti beberapa fakta dari fakta pegawai, fakta pensiun, dan fakta presensi ditampilkan dalam bentuk grafik lingkaran (grafik pie) di tampilan utama menggunakan modul HightChart. Sedangkan untuk melakukan analisis lebih mendalam atau spesifik maka dibuat tempilan tabel menggunakan modul PivotTable.

Gambar 7 menunjukkan sub-sub sistem pada sistem data warehouse yang dibangun. Sub sistem data staging terdiri dari database atau perangkat penyimpanan yang digunakan untuk memuat dan mempersiapkan data oleh sub sistem ETL. Sub sistem ETL berfungsi untuk mempersiapkan data dengan kualitas tertentu dan me-load data yang telah dipersiapkan tersebut ke sub sistem data warehouse. Sub sistem OLAP berfungsi untuk menjalankan proses analisis. Hasil dari proses analisis akan di masukkan ke dalam sub sistem display untuk ditampilkan ke penguna melalui web service.

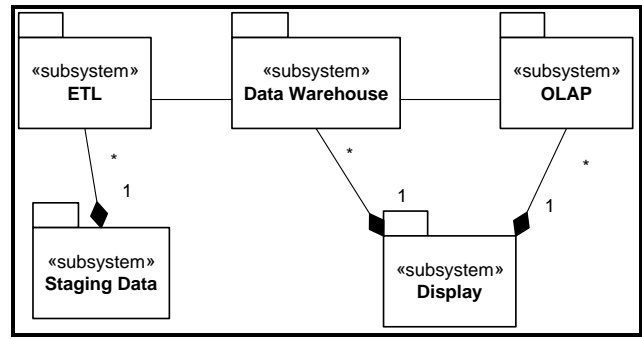

Gambar 7 Sub sistem data warehouse

Sub sistem OLAP dan sub sistem display dibangun dengan arsitektur Model-ViewController (MVC) seperti pada Gambar 8. View adalah sub sistem yang dibangun untuk menangani tampilan ke template tampilan. Berikutnya adalah Controller yaitu bagian yang digunakan untuk melakukan penanganan permintaan pengguna. Sedangkan Model di bangun untuk membuat abstraksi fungsi-fungsi database untuk sub sistem OLAP. 


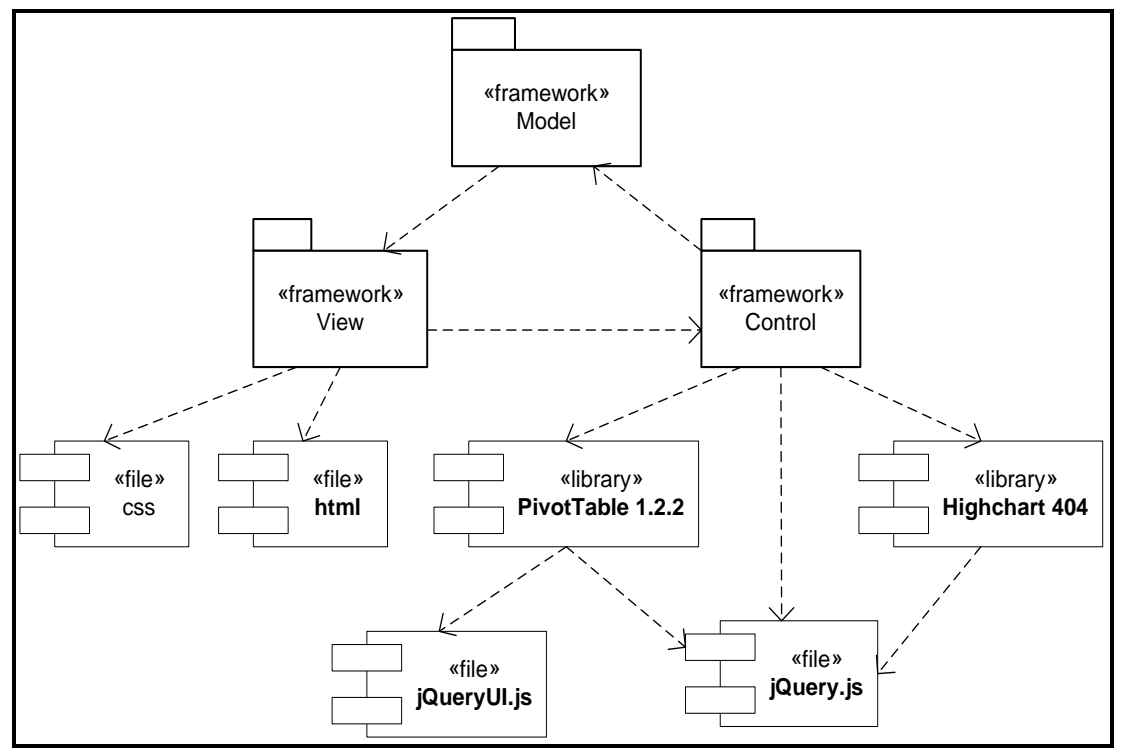

Gambar 8 Framework pengembangan BI

\section{HASIL DAN PEMBAHASAN}

Proses ETL untuk mengisi data masing-masing cube berhasil dilakukan dengan Pentaho Data Integration. Selanjutnya, untuk mempermudah melakukan analisis data, dibangun program aplikasi BI menggunakan jQuery, HightChart 404, PivotTable 122, dan PHP untuk membuat query dinamis dan tampilan dashboard seperti pada Gambar 9.

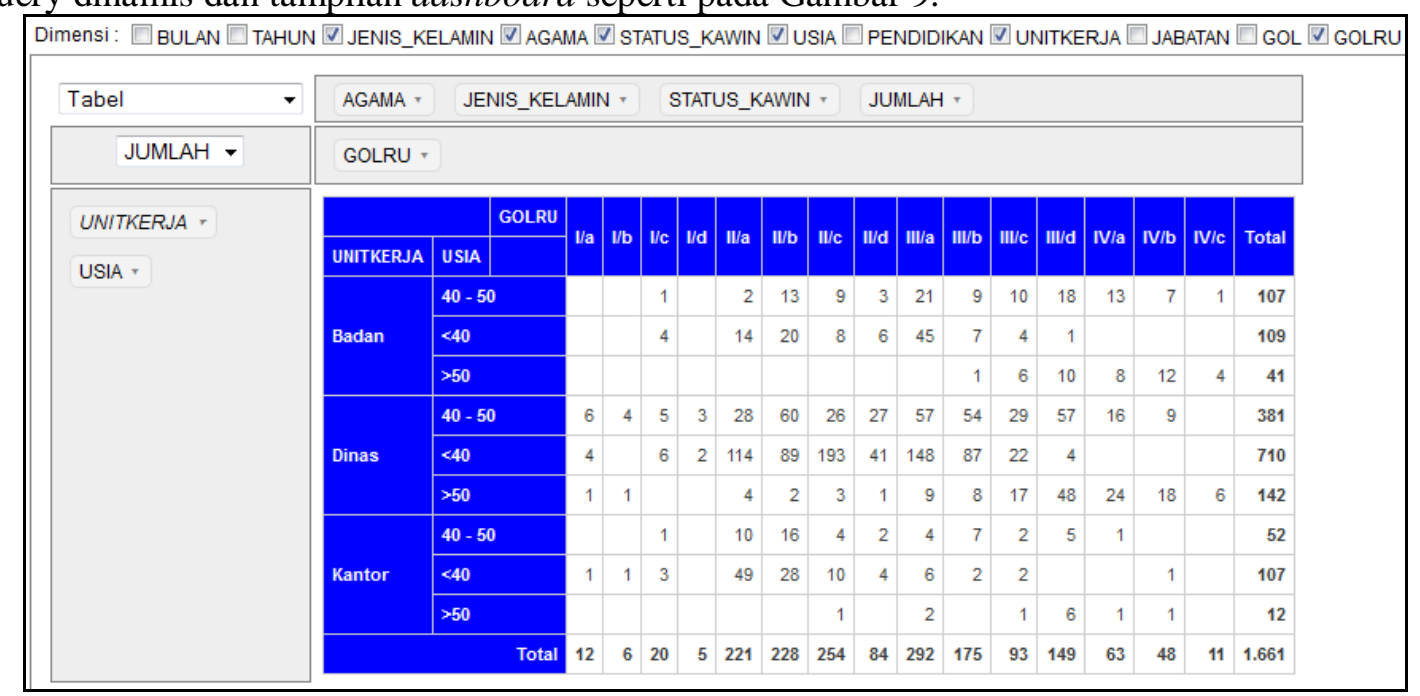

Gambar 9 Dashboard sistem

Hasil OLAP diperoleh informasi PNS sebanyak 3.959 yang dapat dianalisis menurut dimensi bulan, tahun, jenis kelamin, agama, status kawin, usia, pendidikan, jabatan, golongan, golongan ruang, diklatpim, eselon, unit kerja. Hasil OLAP diperoleh informasi PNS naik pangkat sebanyak 685 yang dapat dianalisis dari dimensi tmt, jenis, golongan, golongan ruang, pendidikan, dan unit kerja. Hasil OLAP dengan cube CPNS diperoleh informasi CPNS sebanyak 203 yang dapat ditinjau dari dimensi tahun, keterangan, jenis kelamin, agama, status kawin, usia, pendidikan, jabatan, golongan, golongan ruang, dan unit kerja. Hasil OLAP diperoleh informasi pegawai pensiun sebanyak 27 yang dapat ditinjau dari dimensi jenis pensiun, golongan, golongan ruang, tmt. Sedangkan hasil OLAP menggunakan cube presensi diperoleh informasi presensi tahun 2011 sampai dengan tahun 2012 sebanyak 18.348 record. 
Fakta analisis data presensi berupa jumlah kali presensi, jumlah TPP dan jumlah potongan TPP dapat dianalisis dari sudut pandang bulan, tahun, keterangan, jenis kelamin, agama, status kawin, usia, pendidikan, golongan, golongan ruang, eselon, jabatan, dan unit kerja.

Pengujian adalah tahap lanjutan dari kegiatan pengembangan sistem untuk memujudkan sebuah sistem yang siap untuk digunakan dan berkualitas. Pengujian meliputi pengujian desain dan implementasi data warehouse [18], pengujian sistem, dan pengujian penerimaan pengguna.

\section{KESIMPULAN}

Kesimpulan yang diperoleh dari penelitian ini adalah

1. Telah dirancang dan dibangun data warehouse PNS Kota Tarakan.

2. Hasil pengembangan data warehouse diperoleh model fact constellation dengan jumlah tabel lebih sedikit dibanding dengan jumlah tabel jika menggunakan model star.

3. Telah dirancang dan dibangun program aplikasi OLAP yang dapat membantu pengelolaan SDM PNS Kota Tarakan.

4. Framework BI yang di bangun dapat diintegrasikan dengan template halaman yang disediakan, modul HightChart dan modul PivotTable.

5. Proses ETL berhasil dilakukan dengan menggunakan pentaho data integration.

6. Berdasarkan evaluasi kebergunaan terhadap program aplikasi yang telah dibangun, dapat disimpulkan bahwa:

a. Pengguna menerima dengan baik tampilan program yang diimplementasikan.

b. Pengguna tidak mengalami kesulitan dalam pengoperasian program.

c. Kemampuan sistem dalam menampilkan informasi yang diperlukan pengguna dapat dikatakan sudah mencukupi.

\section{SARAN}

Beberapa hal yang mungkin dikembangkan dari penelitian ini adalah

1. Dashboard dapat disempurnakan untuk mendukung manipulasi tampilan agar lebih fleksibel dan mudah digunakan.

2. Framework BI dapat disempurnakan untuk memberikan kemampuan yang lebih besar dengan implementasi yang lebih mudah.

3. Penelitian ini dapat ditindaklanjuti dengan pengembangan data warehouse PNS tingkat BKN Regional dan data warehouse tingkat BKN pusat sehingga terbentuk data warehouse PNS nasional.

\section{DAFTAR PUSTAKA}

[1] Ashari, E.T., 2010, Reformasi Pengelolaan SDM Aparatur, Prasyarat Tata Kelola Birokrasi yang Baik, Borneo Administrator, 6, 2, 1 - 17.

[2] Anonim, 2009, BKD Kota Tarakan Terunggul dalam Mengelola Kepegawaian, TD Edisi No.5/II, Agustus 2009, Tersedia di http://diklataparatur.blogspot .com/2009/11/bkd-kota-tarakanterunggul-dalam.html [17 September 2014].

[3] Mocka, B. dan Leka, D., 2013, Optimizing Data Warehouse, Journal of Science, Innovation and New Technology, 1, 6, $51-58$.

[4] Coman, M., 2009, Business Intelligence and E-Governance, LESIJ, 16, 1, 484 - 491. 
[5] Velicanu, M. dan Matei, G., 2007, Building a Data Warehouse step by step, Informatica Economica, 2, 42, 83-89.

[6] Chaudhuri, S. dan Dayal, U., 1997, An Overview of Data Warehousing and OLAP Technology, ACM Sigmod Record, 1, 26, $65-74$.

[7] Turban, E., Aronson, J.E. dan Liang, T., 2007, Decision Support Systems and Intelligent Systems, Edisi 7, Prentice Hall, New Jersey.

[8] Imhoff, C., Galemmo, N. dan Geiger J.G., 2003, Mastering Data Warehouse Design Relational and Dimensional Techniques, Wiley Publishing, Inc., Indianapolis.

[9] Ballard, C., Herreman, D., Schau, D., Bell, R., Kim. E., dan Valencic, A., 1998, Data Modeling Techniques for Data Warehousing, Edisi 1, IBM International Technical Support Organization, California.

[10] Agarwal, S., Singh, N. dan Pandey, G.N., 2010, Implementation of Data Mining and Data Warehousing In E-Governance, IJCA, 9, 4, 18 - 22.

[11] Bhanti, P., Kaushal, U. dan Pandey, A., 2011, E-Governance in Higher Education: Concept and Role of Data Warehousing Techniques, IJCA, 1, 18, 15- 19.

[12] Beulah, E.M., 2012, E-Governance in Trading System: Concept and Role of Data Warehousing Techniques, IJCA, Egov, 3, 8-10.

[13] Schneider, M., 2003, A Well-formed Data Warehouse Structures, Workshop DMDW'2003, Berlin.

[14] Widom, J., 1995, Research Problem in Data Warehousing, CIKM ke-4, Baltimore

[15] Alshboul, R., 2012, Data Warehouse Explorative Study, Applied Mathematical Sciences, 6, $61,3015-3024$

[16] Connolly, T. dan Begg, C., 2005, Database Systems A Pratical Approach to Design, Implementation and Management, Edisi 4, Pearson Education Limited, Inggris

[17] Lujan-Mora, S. dan Trujilio, J., 2003, A Comprehensive Method for Data Warehouse Design, $D M D W^{\prime} 03,1,1-14$.

[18] Golfarelli, M. dan Rizzi, S., 2009, A Comprehensive Approach to DataWarehouse Testing, DOLAP 09, USA. 